\title{
Consideraciones sobre el encuentro en Barajas (1963): Una ocasión perdida para las relaciones hispano-marroquíes*
}

\author{
Ana Torres García \\ Universidad de Sevilla
}

RESUMEN: Algunos estudiosos de la historia de las relaciones hispano-marroquies han considerado la entrevista en Barajas entre Franco y Hassan II en julio de 1963 un punto de inflexión en la evolución de los contenciosos territoriales entre España y Marruecos. Sin embargo, al mantenerse en secreto el contenido de aquel encuentro, se desconoce exactamente lo tratado por ambos dirigentes, dando pie al surgimiento de diversas interpretaciones y malentendidos que incluso llegan hasta nuestros días. Basado en documentación diplomática inédita, este artículo analiza las circunstancias fundamentales que rodearon aquel episodio para que sea valorado en sus justos términos: la situación politica interna marroquí, el desafio que planteaba Argelia y el planteamiento ideológico y estratégico de Hassan II, que quedó claramente plasmado en la propuesta de negociación realizada a España en aquel momento. Tras ello se plantean dos conclusiones fundamentales. La primera es que aquel encuentro de jefes de Estado no fue concluyente al no concretarse ningún acuerdo en materia territorial. La segunda es que el gobierno español, al no ser capaz de aprovechar aquellas circunstancias históricas adoptando una po-

* Las siglas que se emplean hacen referencia a los archivos consultados, y son: Archivo General del Ministerio de Asuntos Exteriores, Madrid (AMAE); Archivo de la Fundación Nacional Francisco Franco, Madrid (FNFF); Fondo Castiella, Biblioteca de la Real Academia de la Historia, Madrid (RAH); John F. Kennedy Library, Boston (JFKL); Archivo del Ministerio de Asuntos Exteriores francés, Quai d'Orsay, París (AMAEF). Esta labor investigadora ha sido posible gracias al apoyo recibido en forma de becas y ayudas por parte de las siguientes instituciones: Junta de Andalucía, Universidad de Sevilla y John F. Kennedy Library Foundation. Además, me gustaría agradecer los comentarios y sugerencias de Miguel Hernando de Larramendi, María Dolores López Enamorado, Bernabé López García, Víctor Morales Lezcano, Manuel Moreno Alonso y Rafael Valencia Rodríguez, así como de los evaluadores externos de la revista. 
lítica acorde con los tiempos de la descolonización, perdió la oportunidad de llegar a un acuerdo con Marruecos que le hubiese permitido proteger sus intereses norteafricanos.

Palabras Clave: Marruecos; España; Relaciones Exteriores; Franco; Hassan II; Barajas.

\section{Considerations on the meeting at Barajas (1936): A lost chance for the Spanish- Moroccan relations}

ABSTRACT: Some scholars consider the meeting between Franco and Hassan II at Barajas airport in July 1963 as a turning point in the evolution of the Spanish-Moroccan dispute over Spanish controlled territories in North Africa. Nonetheless, since the content of that meeting was kept secret, we can find still different interpretations and misunderstandings about it. Based on newly available diplomatic documentation, this paper reexamines the factors that led to that meeting in order to shed new light on this historical episode. It describes the Moroccan internal political situation, the challenge represented by Algeria at the time, and the ideological and strategic concept of King Hassan II, which was clearly set out in his negotiation proposal to Spain. After analyzing this, two conclusions are reached. The first one is that this meeting was fruitless, as it did not produce any agreement to solve the territorial disputes between Spain and Morocco. The second one argues that the foreign policy of the Spanish government at the time was shortsighted, because it ignored the decolonization process taking place then at a global scale and did not adopt a realistic stance that could have allowed for securing its interests in North Africa.

KEY WORDS: Morocco; Spain; Foreign Relations; Franco; Hassan II; Barajas.

\section{INTRODUCCIÓN}

En la bibliografía existente sobre las relaciones entre España y Marruecos encontramos la aseveración inexacta de que Franco y Hassan II en su entrevista de Barajas el 6 de julio de 1963 acordaron negociar la retrocesión de Ifni ${ }^{1}$. De hecho, es cierto que en 1963, antes del encuentro en el aeropuerto de la capital española, ya circulaban rumores y ciertas informaciones que apuntaban en esa dirección. Por ejemplo, según la agencia Reuters, la prensa marroquí publicó lo siguiente el 11 de mayo:

La prensa marroquí de la oposición dice hoy que España y Marruecos negociaban un acuerdo secreto según el cual Marruecos tomaría posesión de Ifni y el Saha-

1 Véase, por ejemplo, HERNANDO DE LARRAMENDI, 1997: 359ss. 
ra Español, pero España retendría las ciudades-fortalezas mediterráneas de Ceuta y Melilla. Citando 'fuentes bien informadas', el periódico socialista, Al Tahrir, manifestaba que la toma de posesión por Marruecos del África Occidental española se anunciaría públicamente, pero que el acuerdo sobre Ceuta y Melilla, ciudades situadas en la costa norte de Marruecos que España ha ocupado durante siglos, se mantendría en secreto. El periódico añadía que el acuerdo incluía una cláusula que permitía la participación española en los proyectos económicos de desarrollo en las dos provincias cedidas ${ }^{2}$.

Aunque mayor repercusión tuvo la noticia publicada por Le Monde el 8 de julio de 1963 y recogida por Rachid Lazrak en su obra fundamental Le contentieux territorial entre le Maroc et l'Espagne:

el diario cuenta que, según fuentes españolas, Madrid estaría preparada a hacer concesiones sobre Ifni y los islotes del Mediterráneo si Rabat consiente perpetuar el statu quo en los Presidios ${ }^{3}$.

El desconocimiento de lo sucedido en Barajas ha llegado a afectar incluso a la interpretación del conflicto más reciente entre España y Marruecos. Tras la crisis de la isla de Perejil de julio de 2002 se publicaron diversos artículos tratando de informar sobre su aspecto legal, y se llegó a manifestar que la soberanía de Perejil fue uno de los asuntos objeto de negociación en aquel encuentro de 1963:

los acuerdos secretos que el anterior Jefe del Estado, Francisco Franco, llevó a cabo con el Rey Hassan II de Marruecos, el 6 de Julio de 1963, acuerdos que la diplomacia española bautizó con el nombre de «Espíritu de Barajas». El contenido de esos acuerdos comprendía, en realidad, cuatro cuestiones. La primera consistía en que España debía poner fin a su presencia en el territorio de Ifni en 1969, cosa que efectivamente hizo, como todo el mundo sabe. La segunda era llegar a un entendimiento con Marruecos en torno al territorio del Sahara español, congelando Marruecos durante unos años sus reivindicaciones sobre ese territorio. La tercera fue que Marruecos se olvidara sine die de Ceuta y Melilla, ciudades que España consideraba evidentemente como irrenunciables. Por último, respecto al islote del Perejil, se decidió que pasara a ser una especie de «tierra de nadie», aunque la interpretación correcta debe ser de ninguno de los dos, de forma que ninguno de los dos países tuviera presencia militar o civil permanente en el islote. Ya sabemos que España cumplió los acuerdos, retirando los destacamentos militares del islote. También hizo lo propio con Ifni, mientras que Marruecos no cumplió respecto al

2 El Gobierno marroqui se prepara a renunciar definitivamente a Ceuta y Melilla a cambio de Río de Oro e Ifni, afirma Al Tahrir, FNFF, documento $\mathrm{n}^{\circ} 6346,11$ de mayo de 1963.

3 LAZRAK, 1974: 290. 
Sahara, ni Ceuta y Melilla, frente a las cuales sigue haciendo declaraciones y reivindicaciones de todo tipo ${ }^{4}$.

Estos tres fragmentos ejemplifican la difusión de la interpretación de que en Barajas el futuro de estos territorios se determinó. Sin embargo, no pensamos que esto sea históricamente exacto. Especialistas de la historia de las relaciones entre España y Marruecos, como Domingo del Pino o Francisco Villar, ya señalaron que, a su juicio, parecía más plausible que el encuentro entre Franco y Hassan II se hubiese limitado al comentario de aspectos generales de las relaciones bilaterales, más que a entrar en detalles. Villar desde luego lo califica de «táctica dilatoria» por parte española ${ }^{5}$. De hecho, el mismo Lazrak admite que el programa de aquel encuentro parecía haber sido bastante vago, concluyendo que había fracasado en concretar realmente los principios sobre los que se estaba de acuerdo y que debían de servir como puntos de partida de una futura negociación ${ }^{6}$. En una publicación más reciente, Rosa Pardo señala someramente que, efectivamente, aquella entrevista no fue concluyente?

Dados estos antecedentes historiográficos, este artículo pretende avanzar en nuestro conocimiento de este episodio de relevancia en la evolución de las relaciones hispano-marroquíes y poder valorar su significado en sus justos términos. Para ello se ha recopilado documentación diplomática española, francesa y estadounidense, en parte inédita. El análisis basado en estas fuentes ayuda a comprender las circunstancias que rodearon dichas relaciones bilaterales en el periodo 1956-1963, así como las tensiones entre Rabat y Argel y la inestabilidad interna marroquí, factores todos que se conjugaron para ofrecer una oportunidad a España que, como veremos, el gobierno de Franco desaprovechó.

\section{LAS RELACIONES DE ESPAÑA CON EL MARRUECOS INDEPENDIENTE ANTES DE 1963}

El 2 de marzo de 1956 Francia, oficialmente y de manera unilateral, da por terminado el régimen de Protectorado instaurado por el Tratado de Fez (1912). España hace lo mismo el 7 de abril, cuando se firma en Madrid el acuerdo de transferencia de poderes, la Declaración conjunta hispano-marroquí. ${ }^{8}$

4 BERMEJO GARCÍA, 2002.

5 VILLAR, 1982: 91, 109. PINO, 1983a; 1983b: 80-84. Véase también PARDO, 2007: 81-134.

6 LAZRAK, 1974: 290.

7 PARDO, 2010: 131.

8 En el acto de la firma ni Franco ni Mohamed V estuvieron presentes. Sólo firmaron el documento de Independencia de Marruecos y la Declaración conjunta hispano-marroquí los 
Desafortunadamente, de manera casi inmediata al comenzar el proceso descolonizador, surgieron desavenencias y desencuentros entre España y Marruecos en materia territorial. El nacionalismo marroquí reivindicaba desde los años 40 una independencia completa, que recuperase la integridad territorial que correspondía con la extensión denominada el «Gran Marruecos», planteada originalmente por el líder istiqlalí Allal el-Fasi y reflejada gráficamente en un mapa diseñado por su primo ${ }^{9}$. Originalmente, estas reivindicaciones incluían los siguientes territorios norteafricanos administrados por España ${ }^{10}$ : la zona sur del Protectorado o Tarfaya, entre el río Draa y el paralelo $27^{\circ} 40^{\prime}$ (desde 1912), Sidi Ifni (cedido a España en 1860 y ocupado a partir de 1934) y el Sahara español (donde la presencia española se remontaba a 1884), las ciudades de Ceuta (desde 1580) y Melilla (desde 1496) ${ }^{11}$.

En las conversaciones hispano-marroquíes conducentes a la finalización del régimen de Protectorado, España da por supuesto que los territorios que debe abandonar son la zona norte, el jalifato de Tetuán, y la zona sur, Tarfaya. En ningún momento se tratan los territorios de Ifni, Sahara, Ceuta y Melilla e islotes ${ }^{12}$, y esta ambigüedad complicaría de manera grave las relaciones entre Rabat y Madrid durante los años siguientes ${ }^{13}$.

El eventual traspaso de estos territorios, por tanto, no se haría de forma inmediata y directa tras los acuerdos del 7 de abril de $1956^{14}$, sino que se realizaría con discontinuidad, a base de presiones por parte de Rabat, llegando incluso al conflicto armado en la guerra de Ifni de 1957-1958 ${ }^{15}$, y que en ningún momento fueron ajenas a la propia dinámica interna de la política marroquí. De manera que, desde 1956 y durante décadas, las relaciones entre Espa-

ministros respectivos de ambos países. Véase: YBARRA ENRÍQUEZ DE LA ORDEN, 1998: 258-259.

9 LAZRAK, 1974: 15-30, 278-281.

10 Sobre la acción colonial española en Marruecos véanse las obras de MORALES LEZCANO, 1986; 2002. SALAS LARRAZÁBAL, 1992.

11 Tarfaya no fue retrocedida a la vez que la zona norte, sino en 1958, y Sidi Ifni no lo sería hasta 1969. Por su parte, el Sahara Occidental, formado por las provincias de Saquia elHamra y Río de Oro, fue abandonado por España en 1975.

12 YBARRA ENRÍQUEZ DE LA ORDEN, 1998: 263.

13 Bernabé López García califica al período de 1956 a 1963 como "los años del desencuentro". LÓPEZ GARCÍA, 2007: 307-310.

14 HERNANDO DE LARRAMENDI, 1997: 349-351.

15 La causa fue el ataque del Ejército de Liberación Nacional contra fuerzas españolas en un momento en que Muhammad V estaba ausente en viaje de visita oficial a Estados Unidos. Los españoles necesitaron la ayuda de Francia y acabaron replegándose al mismo enclave de Ifni. Véase LAZRAK, 1974: 256 ss. Sobre la guerra de Ifni consúltense, entre otros: DIEGO AGUIRRE, 1993. YBARRA ENRÍQUEZ DE LA ORDEN, 1998: 332-348. CASAS DE LA VEGA, 2009. 
ña y Marruecos se ven enturbiadas de manera fundamental por desavenencias en materia territorial y, a consecuencia de esto, de pesca ${ }^{16}$.

A pesar de que durante el periodo previo a la independencia España apoyó al nacionalismo marroquí en su oposición a la autoridad protectora francesa e, incluso, se negó a aceptar la imposición del sultán Ben Arafa cuando Sidi Muhammad fue forzado al exilio en 1953, los españoles no supieron sacar beneficio de aquella política ${ }^{17}$. Al contrario, el rechazo a abordar las exigencias territoriales del Marruecos independiente enturbió las relaciones bilaterales ${ }^{18}$.

Poco después de reconocida la independencia de Marruecos, el retraso en la devolución de la zona sur del antiguo Protectorado originó el enfrentamiento que supuso la guerra de Ifni (1957-1958), que tendría como resultado la retrocesión de Tarfaya por el acuerdo de Cintra (1 de abril de 1958). Dicho acuerdo reafirmó la determinación del gobierno español, o quizás más bien de la Presidencia, en querer conservar a toda costa las provincias meridionales de Sidi Ifni y Sahara. España intentó que la devolución de Tarfaya sirviese para poner punto y final a las reivindicaciones de los marroquíes sobre los territorios entonces bajo administración española ${ }^{19}$. Sin embargo, Marruecos en ningún momento lo aceptó 20 .

Otro asunto espinoso fue la cuestión de la evacuación de las tropas extranjeras. La negociación entre Muhammad V y Eisenhower acerca de la evacuación de las bases militares estadounidenses en Marruecos en 1959 propició también el acuerdo de retirada de tropas francesas, que se firmó el 1 de septiembre de $1959^{21}$. El siguiente paso, entonces, para el gobierno marroquí fue dirigir su presión diplomática hacia Madrid con el objeto de que se retirasen la totalidad de los efectivos españoles de suelo marroquí. Pero los españoles se resistían argumentando que eran necesarias medidas de seguridad y garantías sobre Ifni, Sahara, Ceuta y Melilla ${ }^{22}$.

Ante esta actitud, en el verano de 1960 comienza un intercambio epistolar entre Muhammad V y Franco en el que el primero urge la retirada inmediata de las tropas españolas. Según Ybarra, durante la negociación sobre Tarfaya en Cintra el ministro Balafrech acordó que los españoles se replegarían hasta acordar la evacuación total. El requerimiento de Muhammad V en 1960, por

16 Véase LAZRAK, 1974. MORÁN, 1980: 196ss. VILLAR, 1982.

17 Sobre este período de las relaciones hispano-marroquíes véanse las obras fundamentales de ALGORA WEBER, 1995. YBARRA ENRÍQUEZ DE LA ORDEN, 1998.

18 HERNANDO DE LARRAMENDI, 1997: 353.

19 SUÁREZ FERNÁNDEZ, 1984, vol. VII: 299. Sobre el proceso de descolonización de Tarfaya e Ifni véase MONTORO OBRERO, 1988; 1991.

20 LAZRAK, 1974: 282. YBARRA ENRÍQUEZ DE LA ORDEN, 1998: 351.

21 Sobre esta cuestión véase ZARTMAN, 1964. TORRES GARCÍA, 2003.

22 SUÁREZ FERNÁNDEZ, 1984, vol. VII: 232-233. YBARRA ENRÍQUEZ DE LA ORDEN, 1998: 287. 
tanto, iba en contra de lo aceptado por Balafrech en 195923. Con todo, en su última carta enviada a Franco, en diciembre de 1960, el monarca volvía a exigir la retirada, afirmando su decisión de recuperar la integridad territorial de su país. Esta iniciativa también se traduciría en el inicio de las presiones marroquíes contra la presencia española en suelo norteafricano ante el foro de Naciones Unidas. Finalmente, tras la muerte de Muhammad V en febrero de 1961 y, al parecer, para evitar un conflicto con su sucesor, España acepta la evacuación de sus tropas, cuestión que quedará resuelta el 31 de agosto de $1961^{24}$. Sin embargo, este lento proceso y la persistencia de acuerdos bilaterales incumplidos crearon un profundo clima de desconfianza entre ambas partes ${ }^{25}$.

La actitud española se explica en parte por el hecho de que, a principios de los años 60, desde la Presidencia se estimaba probable que España tuviese que hacer frente a una «guerra limitada» en el norte de África, puesto que le había «surgido una frontera sur con un Marruecos independiente que tiene ambiciones imperialistas contra nosotros $\rangle^{26}$.

Este cálculo estratégico, junto con la amenaza del comunismo internacional, era uno de los aspectos que conformaban el planteamiento de seguridad y defensa respecto a los territorios españoles en África, así como de las islas Canarias. Así se le hizo saber a los estadounidenses en diversas ocasiones, tales como en 1961-1962 con ocasión de la concesión de ayuda militar americana a Marruecos; o en 1963 durante las negociaciones de la renovación de los acuerdos de las bases con Estados Unidos, pues uno de los argumentos españoles para reconsiderar los términos de los Convenios lo constituía la aparición de esta nueva amenaza, la posibilidad de un conflicto con Marruecos, que no fue contemplado en $1953^{27}$. Esta percepción española se volvería a plantear en 1968, cuando de nuevo se negociaba la renovación de los acuerdos de las bases americanas en España ${ }^{28}$. Con todo, los estadounidenses siempre dejarían muy claro que ellos se inhibirían totalmente en el caso de que estallase un conflicto entre Marruecos y España ${ }^{29}$.

23 YBARRA ENRÍQUEZ DE LA ORDEN, 1998: 354.

24 YBARRA ENRÍQUEZ DE LA ORDEN, 1998: 298-299. Sobre la operación Repliegue, véase ALBERT SALUEÑA, 24 (Murcia, 2007).

25 MARQUINA BARRIO, 1986: 729-733.

${ }^{26}$ Fragmento citado por Ángel Viñas, proveniente de un informe redactado por el Ministerio de Asuntos Exteriores español con ocasión de la renegociación de los Convenios con Estados Unidos en 1963. VIÑAS, 2003: 342-343.

27 MARQUINA BARRIO, 1986: 747-759, 763. TUSSELL y GARCÍA QUEIPO DE LLANO, 1993: 302-305.

28 DEPARTMENT OF STATE, 2001: 450.

29 VIÑAS, 2003: 343, 362. De hecho, según este autor, Estados Unidos impidió "que el material de su procedencia se utilizara en la campaña de Ifni-Sahara". VIÑAS, 2003: 368. Ybarra corrobora esto, véase YBARRA ENRÍQUEZ DE LA ORDEN, 1998: 295. 
De manera que consideraciones estratégicas, además de económicas ${ }^{30}$, explican la actitud de empecinamiento de Presidencia del Gobierno en mantener bajo control español Sidi Ifni y el Sahara Occidental, a pesar del proceso descolonizador que ya estaba en marcha a escala internacional. La posición contraria, defendida por el ministro de Asuntos Exteriores, Castiella, era calificada por Carrero Blanco, entonces ministro subsecretario de la Presidencia, de «entreguismo» ${ }^{31}$.

\section{TENSIONES CON LA ARGELIA INDEPENDIENTE}

El proceso colonizador francés en el norte de África (1830-1962) extendió los confines argelinos en detrimento de Marruecos al ir estableciendo las autoridades coloniales distintas líneas de separación entre la colonia argelina y el protectorado marroquí de acuerdo con los intereses de las autoridades francesas. De manera que cuando Marruecos se independizó en 1956 el gobierno de Rabat sólo reconocía como legal, por existir un acuerdo internacional que lo avalaba, el tramo de la frontera que iba desde la costa mediterránea hasta Teniet Sassi, unos $150 \mathrm{kms}$ hacia el interior. El resto de los límites con Argelia quedaban por determinar ${ }^{32}$.

En aquel momento, la insurrección argelina ya había estallado y la zona fronteriza sería de gran importancia, tanto para los insurrectos como para los que combatían contra ellos. Por ello, con el fin de controlar de manera efectiva la zona, Francia en 1960 trazó entre Marruecos y Argelia lo que llamó una «línea operacional», siguiendo el río Draa y continuando hacia el noreste, que utilizaría como frontera de facto sin legitimidad legal. Esto alteraba nuevamente los límites en perjuicio de Marruecos, y el gobierno de Rabat no le dio validez a este trazado al considerar que el territorio al sur del río Draa continuando hacia Tinduf ${ }^{33}$ pertenecía al reino alauí. Argelia, por su parte, defendía que ellos heredaban las fronteras establecidas por las autoridades coloniales, por lo que un avance de tropas marroquíes al sur de esa línea sería considerado como una invasión de territorio argelino. Estas desavenencias harían estallar en 1963 el conflicto norteafricano conocido como la Guerra de las Arenas.

Una vez que Argelia se independizó en 1962 y que las fuerzas francesas abandonaron la supervisión de esta región fronteriza, los ejércitos marroquí y

30 España ya explotaba yacimientos de fosfatos en el Sahara Occidental.

31 OREJA AGUIRRE, 2011: 82.

32 Acerca de las fronteras de Marruecos, véase REYNER, 1963. TROUT, 1969. RÉZETTE, 1975.

33 Sobre la reclamación marroquí de Tinduf, véase también ZARTMAN, 1963: 48. RÉZETTE, 1975: 116. HASSAN II, 1988: 97. VERGNIOT, 1991. 
argelino tomarían posiciones en la zona en discordia. Esta presencia militar irremediablemente desembocó en incidentes, que fueron especialmente graves en Tinduf ${ }^{34}$.

Meses después, en la primavera de 1963, Hassan II realizó una visita oficial a Argel, siendo uno de sus principales objetivos el conseguir que los gobernantes argelinos accediese a negociar el trazado de la frontera común. Sin embargo, a pesar de la iniciativa diplomática marroquí, el presidente Ben Be1la rechazó la propuesta argumentando que necesitaba tiempo para consolidar las instituciones del nuevo Estado y que, por ello, no era el momento de plantear los límites territoriales del país ${ }^{35}$. El rey de Marruecos lo explicaría posteriormente así:

Le dije -añadió el Monarca- que Tinduf era ciertamente, entre todas las injusticias la más flagrante y la más patente. Entonces Ben Bella me pidió tiempo para poner en marcha las instituciones argelinas y llegar a ser jefe del Estado. En el mes de octubre -me dijo- tendré la plenitud y la calidad que me permitirán abrir con Vuestra Majestad el expediente de las fronteras, quedando bien entendido que no es cuestión para los argelinos ser pura y simplemente los herederos de Francia en lo que concierne al problema de la fronteras ${ }^{36}$.

La intención de Argel de mantener a toda costa la frontera tal y como la había heredado del colonialismo francés y la insistencia de Rabat en reivindicar la región de Tinduf generó una atmósfera hostil entre ambos vecinos. La tensión se agravaría desembocando en expulsiones de poblaciones fronterizas en un sentido u otro, en el refuerzo de la presencia militar y cierres parciales de la frontera. Finalmente, los ejércitos argelino y marroquí se enfrentaron por el control de los puestos fronterizos de Hassi Beida y Tinyub, al noreste de Tinduf, a partir del 8 de octubre. Días después, los combates se extendieron hacia el norte cuando los argelinos atacaron las poblaciones marroquíes de Ich y Figuig, lejos de la zona en disputa. Finalmente, la Guerra de las Arenas pudo ser contenida gracias a la labor mediadora del presidente de Malí, Modibo Keita, y del emperador de Etiopía, Haile Selassie, y al factor de contención que representaron las políticas adoptadas por las potencias occidentales ${ }^{37}$.

Esta inestabilidad fronteriza coincidió con dificultades internas tanto para el régimen de Ben Bella como para el de Hassan II, ambos viéndose desafia-

34 FLORY, 1 (Paris, 1991): 433. RÉZETTE, 1975: 116. MINISTÉRE DES AFFAIRES ÉTRANGÈRES, $2000:$ 506-509.

35 HASSAN II, 1978: 83. GRIMAUD, 1984: 197.

36 «Hassan II: Ninguna condición previa para negociar un arreglo», España, 25 de octubre de 1963, 6 .

37 Sobre el papel jugado por la diplomacia occidental, particularmente Estados Unidos y España, véase TORRES GARCÍA, 2010. 
dos por importantes fuerzas opositoras. En el caso de Marruecos, además, la oposición al rey contaba con la simpatía y el apoyo del régimen de Argel. En este contexto de inseguridad, tal y como lo percibía el trono alauí, y la posterior negativa del régimen de Ben Bella a negociar un reajuste de frontera, Hassan II intentó fortalecer su posición atribuyéndose un éxito en materia territorial, intentando «recuperar» (según la tesis del Gran Marruecos) territorios considerados como marroquíes y que en aquel momento se encontraban controlados por Argelia o por España.

\section{LA ACCIÓN EXTERIOR DE HASSAN II}

Tras su subida al poder a principios de 1961, Hassan II (1961-1999) utilizó la acción exterior de Marruecos como instrumento para afianzarse en el poder en un momento políticamente difícil debido a la fuerte oposición de izquierdas (Unión Nacional de Fuerzas Populares) y también la nacionalista (Istiqlal). La primera se veía favorecida por el auge de la Argelia republicana y socialista tras la consecución de su independencia. La segunda seguía insistiendo, de mano de su líder Allal al-Fasi, en sus reivindicaciones territoriales con el objetivo de recuperar el «Gran Marruecos». La política del monarca, por tanto, tendrá como uno de sus ejes de actuación la apropiación selectiva del discurso reivindicatorio de territorios considerados marroquíes, un proceso ya iniciado bajo Muhammad V.

En relación a Argelia, como hemos explicado, Hassan II intentaría recuperar la región de Tinduf y, con respecto a España, los territorios susceptibles de reivindicación eran las ciudades de Melilla y Ceuta, los peñones, Ifni y el Sahara Occidental. Otro eje fundamental será mejorar sus relaciones con países como Francia, España y Estados Unidos, dando un giro definitivamente prooccidental a la política exterior del reino alauí, abandonando el neutralismo defendido por su padre Muhammad V ${ }^{38}$.

\section{Intento de acercamiento a España}

Aunque la oposición nacionalista insistía en su discurso irredentista respecto a los territorios norteafricanos controlados por España, Hassan II plan-

38 Berramdane denomina al periodo 1961-1965 «L'amarrage décisif du Maroc au camp occidental». BERRAMDANE, 1987: 225 ss. También, El Houdaïgui señala 1963 como el año en que Hassan II vira en su política hacia Occidente. EL HOUDAÏGUI, 2003: 161. Esta evolución también se recoge en HERNANDO DE LARRAMENDI, 1997: 250. 
teó su propia línea de actuación ${ }^{39}$. Los años 1961 y 1962 habían supuesto un período de difícil vecindad debido al planteamiento de las reivindicaciones de Marruecos sobre Ceuta y Melilla en el foro de Naciones Unidas (1961-1962) y a que, el 30 de junio de 1962, el reino alauí había ampliado la extensión de sus aguas territoriales de 6 a 12 millas, perjudicando seriamente los intereses de la flota pesquera española ${ }^{40}$. Sin embargo, desde 1962 y durante los primeros meses del año 1963, se aprecia un cambio de actitud. Según Domingo del Pino, Hassan II prefirió apaciguar las tensiones con España para centrar sus esfuerzos en el desafío que representaba para su estabilidad la consolidación del régimen revolucionario de Ben Bella en Argelia, y así se lo explicó al general Muñoz Grandes, vicepresidente del gobierno, en su visita de $1962^{41}$. No obstante, Hassan II intentó ganar terreno en ambos frentes: el español y el argelino, aunque en el primer caso siempre por la vía diplomática. Para ello, el monarca dejó muy claro al gobierno español cuál era su propuesta de acuerdo respecto a estos temas en diversas ocasiones y con distintos interlocutores: proponía aparcar la cuestión de los presidios españoles, pero sí negociar la «devolución» de Ifni y el Sahara Occidental.

Desgraciadamente, como describimos a continuación, el monarca marroquí no encontró por parte española una actitud receptiva hacia su iniciativa ${ }^{42}$. Veamos cuáles fueron esos momentos y circunstancias en que Hassan II intentó negociar con España.

\section{Hassan II necesita un éxito en materia territorial}

En relación al gobierno español, la nueva actitud se hizo patente en 1961, cuando el capitán general D. Agustín Muñoz Grandes, jefe del Alto Estado Mayor, viajó a Marrakech en representación de España para asistir a la fiesta de la Independencia de Marruecos que se celebraba el 18 de noviembre. Durante las ceremonias, Muñoz Grandes tuvo la oportunidad de conversar con el monarca:

El Rey recibió a las misiones militares extranjeras una por una deteniéndose con el Capitán General Señor Muñoz Grandes a quien saludó muy expresiva y ca-

39 Sobre la relación entre la evolución del irredentismo marroquí y las tensiones políticas internas entre palacio y oposición, tanto nacionalista como de izquierdas, véase HERNANDO DE LARRAMENDI, 2008.

40 GONZÁLEZ CAMPOS, 2004: 8.

41 PINO, 1983b: 80.

42 Este contratiempo, quizás, junto con la falta de respuesta también a su otro contencioso territorial con Argelia, fuesen factores conducentes a que la tensión regional creciera y terminase por estallar el conflicto fronterizo de la Guerra de las Arenas. 
riñosamente recordando cuando le conoció en España siendo príncipe heredero. Después le encargó un saludo agradecido para S.E. el Generalísimo. Reiteró nuevamente al Capitán General su simpatía y agradecimiento por la misión que se le ha confiado obligándole a desplazarse hasta Marrakech. El Capitán General le dio las gracias y la entrevista terminó con la misma cordialidad y afecto con que había empezado ${ }^{43}$.

De acuerdo con la documentación consultada, en aquel momento Hassan II no hizo ninguna referencia ni solicitó un posible encuentro con el general Franco. Sin embargo, tras aquella ocasión, los marroquíes seguirían estando en contacto con Muñoz Grandes. Esto se desprende de que, en mayo del 1962, el Departamento de Estado informa al encargado de negocios español en Washington, Espinosa, con motivo de una reunión informativa sobre los aviones que Estados Unidos iba a vender a Marruecos, de que tienen la impresión de que Hassan II está decepcionado por la «falta de respuesta española a las iniciativas amistosas planteadas al capitán general Muñoz Grandes en Marraquex ${ }^{44}$. De lo que inferimos que Hassan II aquel noviembre de 1961 ya planteó alguna propuesta de negociación a Muñoz Grandes. De hecho, también sabemos que desde 1962 la diplomacia marroquí ya tenía claramente planteado como objetivo fundamental la anexión de Ifni y el Sahara, los territorios del sur ${ }^{45}$.

Paralelamente a estos contactos cordiales se produjeron hechos no tan amistosos. Como mencionamos anteriormente, el 30 de junio de 1962 Marruecos había ampliado sus aguas jurisdiccionales en perjuicio de España y sus derechos de pesca según los acuerdos bilaterales posteriores a la independencia (1957). Ello había dado lugar a una serie de incidentes, como la captura de pesqueros españoles por parte de los marroquíes, y el consiguiente aumento de la tensión entre los países vecinos ${ }^{46}$. A pesar de todo esto el gobierno de Rabat manifestaba su intención de hacer un esfuerzo por calmar la situación.

El 19 de septiembre de 1962, con ocasión de unas reuniones conjuntas entre el Banco Mundial y el Fondo Monetario Internacional, se reúnen en Washington Abderrahman Tazi, entonces director general de Política Económica del

43 Cordial entrevista del Capitán General Muñoz Grandes con el Rey de Marruecos, RAH, 1520/2, 17 de noviembre de 1961.

${ }_{44}$ Departamento de Estado informa a nuestro encargado de Negocios [Espinosa] sobre la decisión de Estados Unidos de venta de aviones a Marruecos. Hassan II decepcionado por falta de respuesta a iniciativas amistosas planteadas a Capitán General Muñoz Grandes, RAH, 1720/1, 9 de mayo de 1962.

45 González Campos ha señalado que «un diplomático de Marruecos... afirmó que la cuestión de Ceuta y Melilla se suscitaría más tarde, pues lo prioritario en 1961-1962 era la devolución de Ifni.» GONZÁLEZ CAMPOS, 2004: nota 45.

46 VILLAR, 1982: 85ss. 
ministerio de Asuntos Exteriores de Marruecos, y Francisco Giménez Torres, subgobernador del Banco de España. En esa reunión el representante marroquí informa confidencialmente del interés del monarca alauí por celebrar una entrevista personal con Franco para negociar con el gobierno español determinados asuntos de interés mutuo. En concreto, se mencionan como objetivo de dicho encuentro plantear las cuestiones del límite de las aguas jurisdiccionales marroquíes y la explotación de las riquezas petrolíferas del Sahara:

En cuanto al segundo problema se piensa en los medios políticos marroquíes que también por vía de negociación amistosa, pudiera alcanzarse, respecto a la explotación de los posibles yacimientos petrolíferos en el Sahara, una solución similar a la obtenida por Francia en Argelia, esto es autorizando participación de capital marroquí en la explotación e investigación.

Además, se sugiere lo siguiente:

Como preparación de la citada entrevista personal, el Sr. Tazi cree posible que al regreso de su Ministro de Asuntos Exteriores a Rabat procedente de la O.N.U., hacia principios del próximo mes de octubre, se detuviese en Madrid para entrevistarse principalmente con el Excmo. Sr. Vicepresidente del Gobierno, a quien considera especialmente preparado, por razón de su larga permanencia en África, para mantener mejor esta amistosa discusión de las diferencias existentes ${ }^{47}$.

Y así fue. El ministro de Asuntos Exteriores marroquí, Ahmed Balafrech, viajó en visita oficial posteriormente a España, donde permaneció del 24 al 29 de octubre de 1962. Poco después, para corresponder a esta visita, el capitán general Muñoz Grandes se desplazaría a Marruecos en noviembre de ese año, del 17 al 21, con ocasión de la celebración de la fiesta nacional marroquít8. El día 21 Muñoz Grandes se entrevistó con Hassan II y al Ministerio de Exteriores español en Madrid se le informó escuetamente de lo siguiente:

Capitán General Muñoz Grandes fue recibido en audiencia por su Majestad Hassan II asistiendo Presidente Señor Balafrej y Embajador Marruecos en Madrid. Entrevista, que duro más de dos horas, se desarrolló, según me dice Capitán General, en términos de mutua comprensión y deja ambiente preparado para futuras conversaciones $^{49}$.

47 Entrevista celebrada en Washington entre el Ilmo. Sr. Abderrahman Tazi, Director General de Política Económica del Ministerio de Asuntos Exteriores de Marruecos y Don Francisco Giménez Torres, AMAE, legajo 8610, exp. 1, 19 de septiembre de 1962.

48 Detalles de la estancia en Marruecos del Capitán General Muñoz Grandes, RAH, 1894/8, 21 de noviembre de 1962.

49 Entrevista cordial de Hassan II con Muñoz Grandes deja ambiente preparado para futuras conversaciones, RAH, 1895/3, 21 de noviembre de 1962. 
Es reseñable que, tras dos horas de conversación con Hassan II, este sucinto texto fuera lo que se trasladase al Palacio de Santa Cruz. Da la impresión de ser un claro ejemplo de que, en cuanto a Marruecos, Exteriores no sólo estaba subordinado a Presidencia del Gobierno sino que incluso no se le mantenía informado de todo lo referente a las relaciones con dicho país.

Volviendo a los gestos de acercamiento del monarca, en esta visita Hassan II pidió abiertamente que se transmitiese a Franco su solicitud de reunirse con él. La Agencia EFE publicó lo siguiente al respecto:

El Capitán General Don Agustín Muñoz Grandes, Vicepresidente del Gobierno español, ha dado hoy por terminada su estancia oficial en Marruecos, país que ha visitado como invitado de honor con motivo de la celebración de la Fiesta Nacional marroquí. En el Palacio real, el Capitán General español se despidió hoy al mediodía del Monarca marroquí en una solemne ceremonia, en el transcurso de la cual S. M. Hassan II ha expresado el deseo de celebrar una entrevista con el Jefe del Estado español, Generalísimo Franco, bien en Marruecos o en España. El Monarca, que ha entregado al Vicepresidente del Gobierno español las insignias del Cordón de Gran Oficial de la Orden Militar del Trono, la mas alta condecoración marroquí, que le ha concedido con ocasión de este viaje, declaró dirigiéndose a Muñoz Grandes: 'En este salón del trono del Palacio Real es la primera vez que recibo una dignidad tan alta del Gobierno español'. El Monarca reiteró su deseo de que esta entrevista entre los dos Jefes de Estado se celebre en la fecha mas próxima posible, al mismo tiempo que le rogaba transmitiera sus mejores votos para el Caudillo de España.... ${ }^{50}$.

Aunque Franco, al parecer, desestimó la celebración de dicha reunión en aquellos momentos $^{51}$, no hay duda de que la tensión bilateral entre Rabat y Madrid cesó temporalmente y se asentaron las bases de un intento de mejora en la comunicación entre ambos gobiernos. Esta positiva evolución fue reconocida incluso por representantes del gobierno estadounidense que manifestaron al ministro Balafrech su satisfacción por la mejora en la relación bilateral52. Ciertamente, por parte española también se apreciaba la labor diplomática de Ahmed Balafrech. En una posterior conversación con su homólogo francés, el ministro español de Exteriores, Castiella, manifestó que las relaciones con Marruecos habían mejorado claramente «desde tiempos de

50 Nuevas informaciones de la estancia de Muñoz Grandes en Marruecos, RAH, 1896/14, 21 de noviembre de 1962.

51 TOGORES SÁNCHEZ, 2007: 415, 480.

52 Funcionarios norteamericanos manifiestan a Balafrej conveniencia de que Marruecos viva en términos amistosos con su vecina España. Noticia facilitada por la agencia EFE, RAH, 1896/15, 21 de noviembre de 1962. 
Balafrej», comentó que «éste es un hombre honesto con el que ha sido posible convenir ciertos acuerdos de procedimiento que habían sido paralizados $\rangle^{53}$.

Tres meses después de la última visita de Muñoz Grandes, en febrero de 1963, y con motivo de la audiencia de presentación de credenciales como nuevo embajador de España en Marruecos, Manuel Aznar, Hassan II planteó claramente su propuesta al representante español. Éste lo describe y comenta así:

Es [sic] clara alusión a Ceuta y Melilla como problemas que se dejan fuera de la actualidad y que se encomiendan a generaciones futuras. En cambio deja ver claramente su convicción de que otros problemas exigen trámites rápidos, bien que no dijo cuales eran esos problemas.... No hay duda de que el Rey se siente sometido a fuertes presiones por parte de los partidos de izquierda y esas presiones se acentuarán en las próximas campañas electorales,... por eso parece buscar a toda costa algún éxito personal con vistas a mantener popularidad de monarquía y si cabe fortalecerla. Puso especial interés en mostrar su admiración y reverencia hacia nuestro Caudillo, como se deduce del discurso y acentuó sus (?) esperanzas que en su ánimo y en todo gobierno ha promovido reciente visita del Capitán General Muñoz Grandes ${ }^{54}$.

Es obvio que, como sostiene Togores, el capitán general realizó importantes funciones de diplomático ${ }^{55}$. Y en lo que concierne a Marruecos, prosiguió aún unos años más. Incluso llegó a celebrar en 1966 entrevistas secretas en Madrid con Allal el-Fasi, pues, según Gaudio, era partidario de las tesis marroquíes respecto al Sahara ${ }^{56}$. Efectivamente, en la documentación consultada encontramos indicios de que así fue. En diciembre de 1966, Muñoz Grandes hace partícipe al estadounidense Averell Harriman, Ambassador at Large ${ }^{57}$, de su postura respecto al contencioso del Sahara:

...el Vicepresidente del Gobierno, insistiendo mucho que hablaba a título personal, dijo que se podría pensar en una fórmula de cooperación que, manteniendo firmes los lazos de España con el Sahara y la absoluta protección nuestra a la población sahariana, diera la posibilidad de una participación, en la explotación de los recursos naturales de varios órdenes de toda esa área, a los países y poblaciones circundantes... El General Muñoz Grandes, que insistió hablaba a título personal,

53 Entretien Couve-Castiella, AMAEF, Serie: Secretariat General 1945-1966, Sous-serie: Entretiens et messages 1956-66 (Microfilm), vol. 19, documentos 136 y 142, 20 de noviembre de 1963.

${ }^{54}$ Precisiones del Embajador Aznar sobre las palabras de S. M. el Rey Hassan en el acto de la presentación de credenciales, FNFF, documento $\mathrm{n}^{\circ}$ 6349, 9 de febrero de 1963.

55 TOGORES, 2007: 480.

56 GAUDIO, 1978: 201. También citado por VILLAR, 1982: 116. Agustín Muñoz Grandes cesó el 22 de julio de 1967 como vicepresidente del gobierno.

57 Embajador extraordinario para asuntos especiales del presidente Lyndon B. Johnson (1963-1968). 
dijo que él estaba tratando de ganar el consenso en el seno del Gobierno español, para esta política; y que los marroquíes conocían estas ideas y no podían dudar ni de su palabra ni de su amistad ${ }^{58}$.

La posición del entonces vicepresidente del gobierno, a favor de un acuerdo con Marruecos en materia territorial que incluyese cierto tipo de cooperación a favor de los intereses de ambos países, es posible que incidiese favorablemente en el gobierno marroquí y en el español propiciando un periodo de relaciones cordiales mientras se sostuvo el principio de que ambos gobiernos eran proclives a la negociación. Sería por tanto interesante poder contar con más información que arrojase luz sobre la influencia del capitán general y su aportación en el proceso de gestación de lo que se llamaría posteriormente el «Espíritu de Barajas».

\section{Primeros contactos del embajador español Manuel Aznar con el MONARCA ALAUÍ}

Volviendo a los contactos entre Hassan II y el embajador Aznar, sobre el 8 de abril de 1963 el representante español se reunió con el ministro Balafrech $^{59}$, y posteriormente, el día 22 de aquel mes, el rey lo convocó a su palacio de Fez porque «quería confirmar y ampliar algunos de los argumentos e interpretaciones de Balafrej» ${ }^{60}$. En dicha reunión, Hassan II manifestó, una vez más, su deseo de negociar sobre los territorios del sur en manos españolas (es decir, Ifni y Sahara), dejando de lado por el momento Melilla y Ceuta, y ofreciendo una posición ventajosa para España en cuestiones económicas y estratégicas en la zona meridional.

El problema de Ceuta y Melilla, tal como yo lo veo, tal como lo ve el Rey de Marruecos, no lo vamos a resolver ni usted, ni yo; ¿me entiende?; ni la generación de usted, ni la mía. ... Por consiguiente, en este punto, las cosas están muy claras para mí. Todo el «contencioso», en definitiva, se relaciona con los territorios del Sur.

¿Qué puede interesarles a ustedes de esos territorios? ¿Su explotación económica? Marruecos no promovería nunca la menor dificultad para que España participara en cuantas riquezas pudieran obtenerse, fueran mineras, petroleras o de

58 Conversación Muñoz Grandes-Harriman sobre posible cooperación países limitrofes en explotación recursos Sahara, FNFF, documento n ${ }^{\circ}$ 14747, 15 de diciembre de 1966.

59 Hassan II recibe a nuestro Embajador en Rabat, RAH, 2059/36, 22 de abril de 1963.

60 Carta $^{\circ} 9$ de Aznar a Castiella, RAH, 2066/3, 23 de abril de 1963: 1. Este documento también se encuentra disponible en Hassan II suplica al Gobierno español que 'no le deje llegar con las manos vacías a la apertura del Parlamento, en noviembre', FNFF, Documento $\mathrm{n}^{\mathrm{o}}$ 6352, 23 de abril - 11 de julio de 1963. 
cualquier otra índole. ... [Tinduf] Las actividades de los pescadores españoles en toda la Zona marítima del Sahara serían objeto de un acuerdo solemne, y quedarían ampliamente garantizadas.

¿Le preocupan a España las implicaciones estratégicas o militares del Sahara, por su situación respecto de las islas Canarias? Estamos dispuestos también a satisfacer sus aspiraciones a este respecto de la cuestión, y a reservarle soluciones de perfecta seguridad. ¿Qué otra cosa desea el Gobierno español? Dígamela, señor Embajador, dígamela...yo trato de sugerir las posibilidades que se ofrecen a una negociación. Y por ello digo que estamos dispuestos a recibir con espíritu abierto y constructivo todos los deseos de España ${ }^{61}$.

A la vez advertía sobre la indeseable, en su opinión, alternativa de crear un Estado independiente.

Supongamos que optaran ustedes por la creación de Estaditos, de pequeñas organizaciones pseudo-independientes, lo que suele llamarse «Estaditos fantoches», como hay algunos casos... Estarían contribuyendo a difundir elementos de peligrosa inestabilidad. Eso no tendría sentido ${ }^{62}$.

Además, el monarca insistió en que las negociaciones deberían emprenderse en los seis meses siguientes, antes de que comenzasen el curso parlamentario, pues temía que si no conseguía avances en la cuestión territorial la oposición marroquí lo utilizaría para presionar a favor de una posición maximalista en las reivindicaciones de territorios bajo control español.

Le estoy revelando mi pensamiento. Yo veo en todo esto un porvenir muy importante para ustedes y para nosotros. En cambio, la idea de que, un día, España tenga que evacuar esos territorios cediendo exclusivamente a decisiones internacionales, me parece triste e infecunda. ... Para este fin contamos todavía con un periodo durante el cual yo dispondré de una considerable libertad de iniciativa. Dentro de unos seis meses se reunirá el Parlamento de Marruecos. Habrá en él, como ocurre con todos los Parlamentos, más de un demagogo. Si entonces puedo yo presentar algún resultado positivo de mis gestiones, estaré en condiciones de salir al paso de cualquier exceso demagógico... Y todo seguirá por el camino mejor ${ }^{63}$.

Por supuesto, a este argumento del rey habría que añadir su propia preocupación acerca del futuro de su régimen, pues éste también estaba considerando su propia estabilidad interna, por lo que apelaba a su afinidad ideológica con el régimen de Franco:

61 Carta $^{\circ} 9$ de Aznar a Castiella, RAH, 2066/3, 23 de abril de 1963: 5-6.

${ }_{62}$ Carta $^{\circ} 9$ de Aznar a Castiella, RAH, 2066/3, 23 de abril de 1963: 8.

63 Carta $^{\circ} 9$ de Aznar a Castiella, RAH, 2066/3, 23 de abril de 1963: 7. 
Se aprovecharán de nuestra inacción diplomática, y del fracaso de mis esfuerzos, y tratarán de imponerme programas de reclamaciones o de aspiraciones máximas. .. Volveremos a poner sobre el tapete Ceuta, Melilla, todo. ¿Qué podré yo hacer? España se enfadará; Marruecos se enfadará también...Viviremos de espaldas los unos respecto de los otros. Malo para ustedes. Malo para nosotros. Un enorme fracaso. ¿Quién se aprovechará de ello? Las fuerzas de la inestabilidad, que no pierden oportunidad de prosperar. Y ustedes habrán despreciado la ocasión de ayudarse a sí mismos, ayudando al pueblo más seguro y más sólido del África del Norte, del África que llamamos blanca; a un pueblo que forma parte del mundo libre y desea pertenecer a ese mundo cada día con más determinación; a un pueblo que quiere ser barrera contra el comunismo y contra todos los elementos de disolución y de inestabilidad ${ }^{64}$.

De manera que Hassan II, en respuesta a su percepción de encontrarse atravesando un momento especialmente amenazante para el futuro de su régimen monárquico, ofrecía a España una negociación en la que ésta obtendría importantes contrapartidas a cambio de retirar su control directo sobre Ifni y el Sahara.

A los pocos días de celebrada esta entrevista, el embajador Aznar escribió una carta a Castiella en la que defendía aprovechar la oferta del monarca. Tras exponer las ventajas y desventajas de entablar el diálogo que Hassan II solicitaba, Aznar concluía:

En suma: defiendo la negociación; el diálogo. Creo que debería iniciarse, o insinuarse, antes de la próxima asamblea de las Naciones Unidas, con lo que la posición de España en los debates resultará no sólo confortable, sino brillante.

Defiendo la negociación porque estoy convencido de que es un camino hacia extraordinarias ganancias políticas para España; y el otro, el del silencio, se me aparece como la más sombría de las veredas.

Defiendo el diálogo porque, en mi opinión, al régimen nacional, al régimen de Franco, le ha llegado la hora de procurar el prevalecimiento definitivo en el concierto de las naciones, y un sólido sistema de relaciones hispano-marroquíes ayudará cardinalmente a lograrlo.

Defiendo el diálogo porque juzgo de una importancia excepcional para España que Marruecos siga siendo una monarquía y haya en Rabat un Rey, un Sultán, un poder de origen religioso; y nosotros podemos ayudar a que así sea.

La desaparición del trono marroquí traería consecuencias desastrosas sobre una de las zonas geográficas más críticas de Occidente; para nosotros, quizá la más crítica, después de la portuguesa.

Defiendo el diálogo porque tengo el convencimiento de que, andando el tiempo, y no mucho tiempo, se llegará a un fuerte acuerdo de Marruecos con Mauritania, Senegal, Mali y Argelia sobre problemas de fronteras y sobre el destino del

64 Carta $^{\circ} 9$ de Aznar a Castiella, RAH, 2066/3, 23 de abril de 1963: 10-11. 
desierto. Entonces podemos vernos obligados a negociar en condiciones precarias y difíciles ${ }^{65}$.

Sin embargo, esta propuesta no fue bien recibida ni por Franco, ni por Carrero Blanco ${ }^{66}$.

\section{LA REUNIÓN DE LOS JEFES DE ESTADO EN BARAJAS, 6 DE JULIO DE 1963}

Intentando concretar un acuerdo, el rey marroquí seguía insistiendo en encontrarse con el jefe del Estado español. Finalmente, en el verano de 1963 se produjo la entrevista entre Hassan II y Franco en el aeropuerto de Barajas, que vino a representar el punto álgido del conocido período de relativa distensión de las relaciones entre Marruecos y España conocido como «Espíritu de Barajas» y que duró del otoño de 1962 hasta $1965^{67}$.

Un mes antes, la diplomacia marroquí sugirió un encuentro aprovechando una escala técnica en Barajas a la vuelta de un viaje de Hassan II a Francia ${ }^{68}$. Dos días después el ministro de Exteriores, Castiella, informó al embajador en Rabat de que Franco accedía a dicha entrevista y pedía más detalles para prepararlo ${ }^{69}$. Al comunicar Aznar la respuesta afirmativa a su homólogo Balafrech le transmitió lo siguiente:

... Al comunicarle [a Balafrech] ayer la respuesta de VE y la decisión de Su Excelencia el Jefe del Estado le insistí una y otra vez sobre la necesidad rigurosa de que el encuentro de Barajas corresponda en todo instante a la gran dignidad propia de un cambio de impresiones general entre dos Jefes de Estado, evitando todo lo que pudiera turbar esa dignidad y poniendo especial empeño en que la conversación de nuestro Caudillo con [el] Rey de Marruecos no sea otra cosa que una pública confirmación de amistad y una expresión elocuente del espíritu de cooperación y del espíritu de negociación que preside las relaciones hispano marroquíes; pero eliminando de antemano el planteamiento de problemas concretos no madurados todavía ni siquiera en el nivel de los Embajadores y de los Ministros. Aún fui más adelante en esta dirección al formular ante Ministro Balafrej votos porque de

65 Comentario a la declaración del Rey Hassan II, comunicada en mi carta anterior, FNFF, documento ${ }^{\circ}$ 6353, 1 de mayo de 1963: 4.

${ }^{66}$ OREJA, 2011: 86-87.

${ }^{67}$ VILLAR, 1982: 86. HERNANDO DE LARRAMENDI, 1997: 258.

${ }^{68}$ El Ministro de Asuntos exteriores marroquí, Balafrej, reitera a nuestro Embajador el deseo de Hassan II de 'estrechar la mano de Su Excelencia' durante su breve escala técnica en Barajas, RAH, 2123/1, 22 de junio de 1963.

69 El Ministro de Asuntos exteriores marroquí, Balafrej, reitera a nuestro Embajador el deseo de Hassan II de 'estrechar la mano de Su Excelencia' durante su breve escala técnica en Barajas, RAH, 2123/1, 24 de junio de 1963. 
la escala técnica salga ensanchada y fortalecida la relación de amistad personal entre Su Excelencia y el Rey, de modo tal que quede borrada para siempre cualquier impresión anterior que pudiera proyectar alguna sombra, siquiera fuese ligerísima, sobre el diálogo entre Marruecos y España. Debo decir a VE que [el] Ministro Balafrej acogió con excelente espíritu mis manifestaciones adhiriéndose a cuanto en este orden de cosas le expresé, y declarándome que, también a juicio suyo, importaba mucho que la entrevista de Madrid se atuviese a la orientación que mis palabras señalaban, para que la escala técnica de Barajas no resulte en ningún caso un retroceso en el camino que vamos recorriendo, sino una contribución positiva a los propósitos de gran acuerdo futuro y de gran colaboración que a todos nos anima ${ }^{70}$.

Este telegrama no deja dudas acerca de que no se llegaría a ningún acuerdo de importancia, sino que el acto tendría más bien un marcado carácter diplomático y protocolario. Aunque, por supuesto, no hay que perder de vista posibles beneficios a nivel de política interna, esto último de manera clara en el caso de Hassan $\mathrm{II}^{71}$.

Con estas directrices el 3 de julio Castiella y Laraki, el embajador marroquí en Madrid, se reúnen y acuerdan el programa del encuentro en Barajas. Este sería así: Hassan II llegaría a las $13 \mathrm{~h}$ del sábado 6 de julio y habría dos entrevistas, la primera de $13.15 \mathrm{~h}$ a $14.15 \mathrm{~h}$ y la segunda tras el almuerzo, al tomar el café. «La salida de Madrid tendrá lugar cuando los dos Jefes de Estado lo estimen conveniente». El documento no da más detalles ${ }^{72}$.

En la entrevista estuvieron presentes, además de Hassan II y el general Franco, los respectivos embajadores Laraki y Aznar, un hermano del monarca, el vicepresidente del gobierno español, Muñoz Grandes, el ministro de Información y Turismo, Fraga Iribarne, y los respectivos ministros de Asuntos Exteriores, Castiella y Balafrech. Tras la celebración del encuentro se hizo pública una declaración señalando que se habían «examinado los problemas más importantes que interesan a ambos países» ${ }^{73}$. No obstante, el contenido real de la conversación de ambos jefes de Estado se mantuvo en secreto, lo que favoreció que, con el tiempo, apareciesen rumores o informaciones sin contrastar y que acabasen existiendo diferentes versiones de lo que allí se habló. Lo más probable es que Franco se limitase a escuchar a Hassan II «sin dar respuesta alguna que le comprometiese» ${ }^{74}$. En esta línea, admitiendo que

70 El Ministro de Asuntos exteriores marroquí, Balafrej, reitera a nuestro Embajador el deseo de Hassan II de 'estrechar la mano de Su Excelencia' durante su breve escala técnica en Barajas, RAH, 2125/1, 25 de junio de 1963: 1-2.

71 Ya lo apuntó PINO, 1983b, 84.

72 Programa de la entrevista de Su Excelencia con S.M. El Rey de Marruecos, RAH, 2129/2, 3 de julio de 1963.

73 Véase la prensa de aquella fecha. Por ejemplo, Madrid: Su Excelencia el Jefe de Estado español y el Rey de Marruecos se reunieron ayer, La Vanguardia, 7 de julio de 1963: 1.

74 SUÁREZ FERNÁNDEZ, 1984, vol. VII: 99. 
nada concluyente fue acordado, el ministro Balafrech informaría posteriormente al secretario de Estado norteamericano que:

los españoles habían manifestado buenas intenciones [acerca de las cuestiones pendientes] entre los dos países, pero conversaciones serias todavía no habían empezado $^{75}$.

\section{REUNión DE HASSAN II CON EL MINISTRO FrAGA}

Ante la ausencia de respuesta por parte de España a las propuestas que venía realizando desde 1962, Hassan II reiteró su solicitud de entablar negociaciones imprimiendo un tono dramático aquel mismo mes de julio de 1963. Sólo días después de la entrevista en Barajas, se veía en la necesidad de insistir a los españoles en que el plazo se le acababa, pues la sesión parlamentaria comenzaría en el mes de noviembre siguiente.

El 9 de julio llegó de visita oficial a Marruecos el ministro de Información y Turismo, Manuel Fraga Iribarne. El ministro español fue agasajado en su visita con todo tipo de atenciones y varias entrevistas con el rey:

Al final de la audiencia el monarca impuso a nuestro ministro de información el gran cordón de la orden 'Uissam Alauita', lo que dio ocasión a que se pronunciaran nuevamente palabras de recíproca consideración y afecto. La ceremonia estuvo revestida de un alto rango protocolario confirmándose el éxito de la visita ministerial que no deja de ofrecerse con altas calidades en cada uno de los homenajes que recibe... Al término de la visita a Hassan II indicó éste que esperaba verle de nuevo para seguir examinando en líneas generales el panorama abierto en el comunicado de la conversación de Barajas $^{76}$.

El ministro disfrutó de una amplia agenda de actividades que subrayaba el buen momento de las relaciones bilaterales:

[la] jornada de ayer fue de una incesante actividad para ministro Fraga Iribarne y para este embajador que le acompaña. Desde las ocho de la mañana hasta la una de la madrugada siguiente fue un constante participar en fiestas y celebraciones durante las cuales continuó el ministro Fraga siendo objeto de las más delicadas deferencias personales. ... A reserva de informar a V.E. con mayores detalles sobre este viaje oficial del ministro español de información, deseo adelantarle la seguridad de

75 Memorandum of conversation Secretary-Balafrej, JFKL, National Security Files, Box 438, Morocco 1/61-11/63 [Folder 2 of 2], 2 de octubre de 1963.

76 Telegrama $n^{\circ} 433$ del Embajador en Rabat, RAH, 2136/4, 9 de julio de 1963. 
que ha constituido un gran éxito oficial y personal y una excelentísima colaboración en el trámite de las relaciones entre los dos países y los dos gobiernos ${ }^{77}$.

Además de sobre el aspecto protocolario, el embajador informó a Madrid de la reunión del ministro español con Hassan II el día 11 de julio, en la cual estuvieron presentes también el ministro marroquí de Asuntos Exteriores, Balafrech, el ministro marroquí de Información, Butaleb, y el embajador español:

Durante cerca de media hora [el] Rey expuso al Señor Fraga, rogándole que diera traslado de todo ello al Caudillo, su pensamiento muy concreto sobre las relaciones hispano-marroquíes y sus ideas sobre los diálogos y trato venideros. ... Ha hecho frecuentes alusiones a dicha entrevista de Fez [en el mes de abril anterior] y ha enriquecido o aclarado las ideas que entonces me comunicó con matiz y acento de muy alto interés a mi juicio. El aplazamiento «sine die» por tres o cuatro generaciones - han sido sus palabras- de cualquier diálogo sobre Ceuta y Melilla, la conformidad con que España posea una gran base militar estratégica en el Sahara y una participación preferentísima en la riqueza posible del desierto; y, en definitiva, la imperiosa necesidad de pensar en alguna forma de gran pacto hispano-marroquí para presentar un frente común o mejor dicho una barrera común contra el comunismo han sido los temas centrales de la exposición del Rey; con la reiterada advertencia, que casi se convertía en súplica, de que no se le deje llegar con las manos vacías a la apertura del parlamento marroquí a fines de noviembre de este año porque ello le colocaría en situación muy enojosa y delicada.

Para mí la novedad de esta entrevista de hoy respecto de la Fez ha estado en la aspiración que Hassan II ha dejado entrever con bastante claridad de encaminar las cosas hacia formas de cooperación, de entendimiento y de acuerdo que por momentos parecían adoptar los perfiles de una verdadera alianza, aunque esta palabra no se haya pronunciado en ningún momento ${ }^{78}$.

Unos días después, el embajador de España en Rabat enviaba a Madrid una carta-informe en la que repetía, de manera más extensa, lo tratado con Hassan II en aquella audiencia y que reflejaba profusamente el pensamiento del monarca en aquellos momentos.

Considero que no te parecerá improcedente, ni vano, el hecho de que yo recoja en esta carta un esquema, nada más que un esquema, del pensamiento de Hassan II; y con ello te ofrezca una versión resumida y esencial de la entrevista, a manera de complemento y apéndice de la exposición que haya hecho el Ministro de Información ${ }^{79}$.

77 Telegrama $n^{\circ} 437$ del Embajador en Rabat, RAH, 2138/7, 10 de julio de 1963.

78 Hassan II suplica al Gobierno español que 'no le deje llegar con las manos vacías a la apertura del Parlamento, en noviembre', FNFF, documento ${ }^{\circ} 6352,11$ de julio de 1963.

79 Carta-informe de nuestro Embajador en Rabat sobre la entrevista de Fraga con Hassan II, RAH, 2144/2, 17 de julio de 1963: 1. 
Explicando la amenaza que suponía el surgimiento de la joven república socialista argelina, tanto para Marruecos como para España, el monarca indicaba que:

Sobre la acción de Nasser en Mauritania y sobre la situación explosiva de Argelia, Hassan II vino a querer explicarnos que el socialismo árabe no es sino la vanguardia de una acción moscovita mucho más potente ${ }^{80}$.

\section{Respecto a los contenciosos bilaterales, Hassan II volvía a insistir en su propuesta ya anteriormente realizada:}

'De los problemas territoriales que puedan existir entre España y Marruecos - el rey puso énfasis especial en estas palabras suyas - hay uno que no es para que lo tratemos nosotros; el de Ceuta y Melilla. Si acaso será tema de estudio dentro de dos o tres generaciones, y aún más... Luego vienen los pequeños asuntos de Ifni y de los Peñones. Y finalmente, el Sur.' Vuelve a repetir que España tendría preferencia en la explotación de riquezas de la zona y podría establecer base militar como garantía militar para esta región. 'Ustedes son mucho más fuertes que nosotros. Yo no puedo desear nada mejor que la existencia de una base española en la costa atlántica del Sahara'81.

Posteriormente, hacía referencia al calendario parlamentario que iba a estrenar Marruecos:

... unos y otros -prosiguió el monarca- tenemos nuestros problemas interiores. Yo no desconozco los que el Caudillo ha de tener en cuenta, pero ruego que se aprecien los que a mí me preocupan. La diferencia entre ustedes y nosotros, a este respecto, es que yo tengo sobre mí un plazo, el del 19 de Noviembre próximo, fecha en que deberá reunirse el Parlamento marroquí. Piénsenlo ustedes. No debo llegar a esa fecha con las manos vacías. Quisiera estar, ante la posible demagogia de una parte de las Cámaras, en situación de presentar algún resultado concreto y claro de mi política de amistad y de acuerdo con España. Así sería fácil a mi Ministro de Asuntos Exteriores, o a mi primer Ministro o a mí mismo, salir al paso de las demasías de la oposición y de las exageraciones demagógicas, diciendo: 'Dejadnos tranquilos, porque nuestros métodos de diálogo con España son eficaces y dignos y a ellos hemos de seguir atenidos' ${ }^{\prime 2}$.

Finalmente, el embajador Aznar explicaba la concepción de Hassan II de su país como una isla:

80 Carta-informe de nuestro Embajador en Rabat sobre la entrevista de Fraga con Hassan II, RAH, 2144/2, 17 de julio de 1963: 2.

${ }^{81}$ Carta-informe de nuestro Embajador en Rabat sobre la entrevista de Fraga con Hassan II, RAH, 2144/2, 17 de julio de 1963: 4-5.

82 Carta-informe de nuestro Embajador en Rabat sobre la entrevista de Fraga con Hassan II, RAH, 2144/2, 17 de julio de 1963: 5-6. 
Cuando Hassan II instaba, y rogaba que se aceptase el principio de una negociación, tal como él la iba dibujando, adquirían sus palabras, en algunos momentos, tono de encendida súplica. Así, por ejemplo, cuando explicó: 'Marruecos es hoy una isla. Estamos rodeados por el Atlántico, el Mediterráneo, Argelia y Mauritania. Se nos quiere aislar. Argelia y Mauritania pueden ser los grandes instrumentos de la subversión para hacer más decisivo ese aislamiento. ¿Piensa España en el interés que tiene para ella esto que estoy diciendo? Nosotros somos la ciudadela de esta zona del mundo contra el comunismo. Necesitamos que nos ayuden a cumplir la misión que ello nos impone. El fortalecimiento de un Marruecos pacífico y progresivo, y la solidez del régimen nacional marroquí (del trono), no pueden ser indiferentes para los españoles. Juntos tenemos que luchar contra los factores de destrucción que tratan de envolvernos' 83 .

La audiencia concluiría con la solicitud al ministro Fraga de trasladar todo esto al Caudillo. El ministro español, evitando cuestiones concretas, hizo algunas consideraciones «de carácter general en favor de una gran colaboración hispano-marroquí...» y finalizó comentando que en aquel momento empezaban las vacaciones de verano por lo que el Monarca no debería esperar ninguna iniciativa política de envergadura durante el mes de agosto ${ }^{84}$.

\section{CONCLUSIONES}

A raíz de todo lo expuesto en este artículo, queda demostrado que Hassan II, en el período 1962-1963, buscaba algún éxito diplomático relacionado con las reivindicaciones territoriales enarboladas por elementos de la oposición nacionalista, que le ayudase a estabilizar su posición política interna, muy cuestionada en aquellos momentos.

Si el encuentro en Barajas hubiese sido fructífero, y se hubiese concretado la retrocesión a Marruecos de alguno de los territorios que éste reivindicaba a España, como se ha llegado a publicar, entonces ¿por qué sólo unos días después, aprovechando la visita de Fraga, Hassan II vio la necesidad de insistir en su propuesta de negociación al gobierno español? ¿Por qué iba Hassan II a reiterar, repitiendo una y otra vez a Embajador, Jefe de Estado y Ministro, los mismos argumentos y en tanto poco tiempo?

Es interesante señalar también que de la documentación consultada se desprende que entre los medios diplomáticos españoles existían elementos favorables a la negociación con Marruecos con el objeto de mantener las mejores relaciones posibles con el vecino (por ejemplo, el embajador Aznar). Sin embargo, desde Presidencia del Gobierno el asunto claramente se analizaba de

83 Carta-informe de nuestro Embajador en Rabat sobre la entrevista de Fraga con Hassan II, RAH, 2144/2, 17 de julio de 1963: 6-7.

${ }^{84}$ Carta-informe de nuestro Embajador en Rabat sobre la entrevista de Fraga con Hassan II, RAH, 2144/2, 17 de julio de 1963: 7. 
manera distinta, pues tanto Franco como Carrero Blanco no eran nada partidarios de desprenderse del Sahara. De hecho, la insistencia de Marruecos realmente no se vería satisfecha hasta 1967, cuando empezaron las negociaciones sobre la retrocesión de Ifni, que de manera efectiva tendría lugar en 1969.

Por tanto, la visión de Presidencia del Gobierno prevaleció por encima de voces contrarias provenientes del Ministerio de Exteriores. La coyuntura política interna marroquí y la rivalidad regional con Argelia propiciaron la disposición de Hassan II a adoptar una postura realista respecto a los territorios norteafricanos que hubiese podido favorecer un acuerdo con el gobierno español, en vez de prolongar una situación colonial ya claramente anacrónica.

Todo ello, junto a las convicciones ideológicas de Hassan II a favor de alinearse con Occidente, le hacían vislumbrar un acercamiento a España que fortaleciese un eje atlántico España-Marruecos frente a un posible eje Argelia-Mauritania. Este planteamiento, sin embargo, no obtendría respuesta alguna por parte del gobierno del país vecino.

\section{BiBLIOGRAFÍA}

Albert Salueña, Jesús, «Repliegue del Ejército Español en la Zona Norte el Protectorado en Marruecos», Anales de Historia Contemporánea, 23 (Murcia, 2007): 199-220.

Algora Weber, María Dolores. Las relaciones hispano-árabes durante el régimen de Franco: La ruptura del aislamiento internacional (1946-1950), Madrid, Ministerio de Asuntos Exteriores, 1995.

Bermejo García, Romualdo, Algunas cuestiones jurídicas en torno al islote del Perejil [en línea], Madrid, Real Instituto Elcano, 2002. Disponible en:

http://www.realinstitutoelcano.org/wps/portal/rielcano/contenido?WCM_GLOBAL_ CONTEXT=/elcano/elcano_es/zonas_es/defensa+y+seguridad/ari+25-2002 [consultado el 23 de junio de 2011]

Berramdane, Abdelkhalek, Le Maroc et l'Occident, París, Karthala, 1987.

Casas de la Vega, Rafael, La última guerra de África: (Campaña de Ifni-Sáhara), Madrid, Ministerio de Defensa, 2009.

Department of State, Office of the Historian. Foreign Relations of the United States, 1964-1968. Western Europe. Washington, DC, United States Government Printing Office, 2001.

Diego Aguirre, José Ramón, La última guerra colonial de España: Ifni-Sáhara (1957- 1958), Málaga, Algazara, 1993.

Flory, Maurice, «Chronique diplomatique», en Maurice Flory y Jean-Louis Miège (resp.), Annuaire de l'Afrique du Nord 1 (Paris, 1991): 419-438.

Gaudio, Attilio, Le dossier du Sahara Occidental, París, Nouvelles Éditions, 1978.

González Campos, Julio D., Las pretensiones de Marruecos sobre los territorios españoles en el Norte de África (1956-2002) [en línea], Madrid, Real Instituto El- 
cano, 2004. Disponible en: http:/www.realinstitutoelcano.org/documentos/98/DT15-2004-E.pdf [consultado el 17 de agosto de 2011].

Grimaud, Nicole, La politique exterieur de l'Algérie, París, Karthala, 1984.

Hassan II, The Challenge, the memoirs of King Hassan II of Morocco, Londres, Macmillan, 1978.

Hassan II, El desafio, Barcelona, Libergraf, 1988.

Hernando de Larramendi, Miguel, La politica exterior de Marruecos, Madrid, Mapfre, 1997.

Hernando de Larramendi, Miguel, «Ideología y política en el Marruecos postcolonial», en Congreso Internacional La conferencia internacional de Algeciras de 1906: cien años después, Algeciras, Fundación Municipal de Cultura José Luis Cano, 2008; 307-320.

Houdaïgui, Rachid El, La politique étrangère sous le règne de Hassan II, París, L'Harmattan, 2003.

Lazrak, Rachid, Le contentieux territorial entre le Maroc et l'Espagne, Casablanca, Dar El Kitab, 1974.

Marquina Barrio, Antonio, España en la política de seguridad occidental: 19391986, Madrid, Ediciones Ejército, 1986.

Ministére des Affaires Étrangères, Documents Diplomatiques Français, 1963 (1er janvier-30 juin), París, Imprimerie Nationale, 2000.

Montoro Obrero, Guadalupe, «África Occidental española ante la descolonización de Marruecos (1956-1958)», en: Víctor Morales Lezcano (ed.), III Aula Canarias y el Noroeste de África, Las Palmas de Gran Canaria, Cabildo Insular de Gran Canaria, 1993; 247-270.

Montoro Obrero, Guadalupe, «La retrocesión de Tarfaya e Ifni», Espacio, tiempo y forma. Serie V, Historia contemporánea, 4 (Madrid, 1991): 181-190.

Morales Lezcano, Víctor, El Protectorado en Marruecos, (1912-56): España y el Norte de África, Madrid, UNED, 1986, $2^{\text {a }}$ ed.

Morales Lezcano, Víctor, El colonialismo hispano-francés en Marruecos (18981927), Madrid, Siglo XXI de España, 2002.

Morán, Fernando, Una politica exterior para España: una alternativa socialista, Barcelona, Planeta, 1980.

Oreja Aguirre, Marcelino, Memoria y esperanza: relatos de una vida, Madrid, La Esfera de los Libros, 2011.

Pardo Sanz, Rosa, «El proceso de descolonización», en: Marcelino Oreja Aguirre y Rafael Sánchez Mantero (eds.), Entre la historia y la memoria: Fernando María Castiella y la política exterior de España (1957-1969), Madrid, Real Academia de Ciencias Morales y Políticas, 2007; 81-134.

Pardo Sanz, Rosa, «Fernando María Castiella y la política española hacia el mundo árabe, 1957-1969», en Bernabé López García y Miguel Hernando de Larramendi 
(eds.), España, el Mediterráneo y el mundo arabomusulmán. Diplomacia e historia, Barcelona, Icaria Editorial, 2010.

Pino, Domingo del, «Ceuta y Melilla, las plazas de la discordia», Historia 16, 85 (Madrid, 1983a). Disponible en:

http://www.domingodelpino.com/index.php?id=312 [consultado el 23 de junio de 2011]

Pino, Domingo del, La última guerra con Marruecos: Ceuta y Melilla, Barcelona, Editorial Argos Vergara, 1983b.

Reyner, Anthony S. «Morocco's International Boundaries: A Factual Background», The Journal of Modern African Studies, 1/3 (Cambridge, 1963): 313-326.

Rézette Robert, Le Sahara occidental et les frontières marocaines, París, Nouvelles Éditions Latines, 1975.

Salas Larrazábal, Ramón, El Protectorado de España en Marruecos, Madrid, Mapfre, 1992.

Suárez Fernández, Luis, Francisco Franco y su tiempo, Madrid, Fundación Nacional Francisco Franco, 1984, vol. VII.

Togores Sánchez, Luis Eugenio, Muñoz Grandes: héroe de Marruecos, general de la División Azul, Madrid, La Esfera de los Libros, 2007.

Torres García, Ana, Limitaciones de una política exterior norteamericana: sindicalismo y nacionalismo en Marruecos (1956-1959), Sevilla, Alfar, 2003.

Torres García, Ana, Historia de las relaciones exteriores del Marruecos independiente: La Guerra de las Arenas (1963) y la diplomacia occidental, tesis doctoral inédita, Sevilla, Universidad de Sevilla, 2010.

Trout, Frank E., Morocco's Saharan frontiers, Geneva, Droz Publishers, 1969.

Tussell, Javier y Genoveva García y Queipo de Llano, Carrero: la eminencia gris del régimen de Franco, Madrid, Temas de Hoy, 1993.

Vergniot, Olivier, «La question du Sahara Occidental. Autodétermination et enjeux référendaires (1956-1989)», en Michel Camau y Jean-Claude Santucci (resp.), Annuaire de l'Afrique du Nord, Paris, Editions du CNRS, 1991; 28: 385-418.

Villar, Francisco, El proceso de autodeterminación del Sahara, Valencia, Fernando Torres, 1982.

Viñas, Ángel, En las garras del águila: los pactos con Estados Unidos, de Francisco Franco a Felipe González (1945-1995), Barcelona, Crítica, 2003.

Ybarra Enríquez de la Orden, María Concepción, España y la descolonización del Magreb: rivalidad hispano-francesa en Marruecos (1951-1961), Madrid, UNED, 1998.

Zartman, I. William, «The Sahara - bridge or barrier?», International conciliation, 541 (Nueva York, 1963): 42-50.

Zartman, I. William, Morocco: Problems of New Power, Nueva York, Atherton Press, 1964. 